\title{
Degradação ruminal in situ do capim-elefante (Pennisetum purpureum, Schumack) consumido sob pastejo por vacas mestiças Holandês $\times$ Zebu em lactação
}

\author{
[Rumen degradability of elephantgrass (Pennisetum purpureum, Schumack) grazed by \\ lactating crossbred Holstein $\times$ Zebu dairy cows] \\ F.C.F. Lopes ${ }^{1}$, L.J.M. Aroeira ${ }^{1}$, N.M. Rodriguez ${ }^{2}$, F. Deresz ${ }^{1}$, I.B.M. Sampaio ${ }^{2}$, \\ I. Borges ${ }^{2}$, H. Maldonado-Vasquez ${ }^{3}$, A. Vittori ${ }^{4}$ \\ ${ }^{1}$ Embrapa Gado de Leite \\ Rua Eugênio do Nascimento, 610 \\ 36038-330 - Juiz de Fora, MG \\ ${ }^{2}$ Escola de Veterinária da UFMG - Belo Horizonte, MG \\ ${ }^{3}$ Universidade Estadual Norte Fluminense - Campos dos Goytacazes, RJ \\ ${ }^{4}$ Doutoranda no Departamento de Zootecnia da UFV - Viçosa, MG
}

Recebido para correspondência em 22 de novembro de 2002

Recebido para correspondência, após modificações, em 24 de abril de 2003

E-mail: fcfl@cnpgl.embrapa.br

\section{RESUMO}

Dois experimentos foram conduzidos em pastagem de capim-elefante manejada em sistema rotativo. Foram utilizadas duas repetições de área por tratamento e três dias de ocupação do piquete. No primeiro experimento (estação da seca) foram usadas 18 vacas Holandês $\times$ Zebu em lactação, sendo seis fistuladas no rúmen. Foram estudados período de descanso da pastagem de 30 dias, sem uso de concentrado, e períodos de descanso de 30 e 45 dias, com uso de concentrado. Entre ordenhas, as vacas receberam canade-açúcar com 1\% de uréia:sulfato de amônio (9:1). Amostras de extrusas (três dias de pastejo $\times$ duas repetições de área de pastagem) foram incubadas no rúmen das vacas fistuladas. No segundo experimento (estação das chuvas) foram usadas 12 vacas em lactação (quatro fistuladas no rúmen) e similar procedimento para estudo de dois períodos de descanso da pastagem (30 ou 45 dias) sem suplementação. A partir do primeiro dia de ocupação do piquete houve diminuição na qualidade da forragem selecionada. Na seca foi observada menor degradabilidade efetiva (DE) no terceiro dia de ocupação do piquete. No período das chuvas a DE foi semelhante nos três dias de ocupação do piquete. Maior DE e melhor qualidade da forragem foram verificadas para períodos de 30 dias de descanso da pastagem.

Palavras-chave: degradabilidade, dia de ocupação do piquete, extrusa, pastejo rotativo, período de descanso

\begin{abstract}
Two experiments were carried out in a rotational elephantgrass pasture system. Two replicates of paddocks per treatment were grazed for three consecutive days. The first experiment was carried out during the dry season with 18 lactating crossbred cows, six of them rumen canulated. The cows were randomly allotted to each of the treatments: 1-resting period of 30 days without concentrate, 2- resting period of 30 days with concentrate and 3-resting period of 45 days with concentrate. In the dry season cows grazed elephantgrass during the night and were fed chopped sugarcane plus $1 \%$ ammonium sulphate:urea (9:1) between milkings. Elephantgrass extrusas were collected by treatment during the first, second and third grazing days and were incubated in the rumen of the canulated cows. In the second trial carried out during the rainy season 12 lactating crossbred cows (four rumen canulated) were used. The treatments were resting periods of 30 or 45 days without supplementation. Decreases of extrusa
\end{abstract}


quality were observed from first to third occupation day of paddock. During the dry season the lowest value of effective degradability (ED) was observed at third day of paddock occupation. During the rainy season similar ED were obtained for the three days of paddock occupation. The treatment with 30 days resulted in a better quality of herbage and higher ED than treatment with 45 days.

Keywords: degradability, occupation day of paddock, extrusa, rotational grazing, resting period

\section{INTRODUÇÃO}

A despeito de preocupações manifestadas por diversos autores (Nocek, 1988; National..., 2001) quanto à sua padronização, a técnica in situ ou in sacco (Mehrez, Ørskov, 1977) tem sido, por fatores inerentes à simplicidade e baixo custo, amplamente usada para estimar parâmetros de degradação ruminal dos alimentos (National..., 2001).

A forma modificada por Sampaio (1988) da equação proposta por Mehrez e Ørskov (1977) identifica, de modo explícito, dois (taxa e potencial de degradação) dos principais elementos de qualificação de forrageiras (Barbi et al., 1995). Para responder pelos efeitos inerentes à dinâmica da passagem da digesta no rúmen, Ørskov e McDonald (1979) sugeriram o uso de uma equação para obtenção de valores de degradabilidade efetiva dos nutrientes.

Atualmente, percebem-se na literatura alguns trabalhos (Benedetti, 1994; Codagnone et al., 1998; Lopes, Aroeira, 1999) e muitas lacunas de informações, que evidenciam a necessidade de estudos adicionais concernentes à degradação ruminal in situ dos nutrientes do capim-elefante (Pennisetum purpureum, Schumack) sob pastejo de vacas em lactação.

Foi objetivo do presente trabalho estudar a degradação ruminal in situ do capim-elefante sob pastejo de vacas mestiças Holandês $\times$ Zebu em lactação.

\section{MATERIAL E MÉTODOS}

Dois experimentos foram conduzidos nos anos de 1993 (estação da seca) e 1995 (estação das chuvas) na Embrapa Gado de Leite (Coronel Pacheco, MG). ) em pastagem de capim-elefante dividida em piquetes e manejada em sistema rotativo. O período de ocupação dos piquetes foi de três dias, com duas repetições de área de pastagem por tratamento.

O primeiro experimento foi conduzido na estação da seca (agosto e setembro) de 1993. Foram usadas 18 vacas mestiças Holandês $\times$ Zebu em lactação, sendo seis fistuladas no rúmen (cânulas de plastosol de 10 cm de diâmetro interno de abertura). As vacas fistuladas estavam, em média, com $142 \pm 23$ dias da segunda ou terceira lactação. As 18 vacas foram distribuídas nos tratamentos em delineamento de blocos ao acaso, de acordo com a produção de leite e peso vivo, registrados no período pré-experimental. Em cada repetição de área de pastagem de cada tratamento foi alocada uma vaca fistulada no rúmen.

Os tratamentos foram períodos de descanso da pastagem de 30 dias, sem uso de concentrado, e de 30 e 45 dias, com uso de concentrado ao longo do ano. O concentrado, com 85,0\% de matéria seca (MS), 20,7\% de proteína bruta (PB), 23,7\% de fibra em detergente neutro (FDN) e 8,4\% de fibra em detergente ácido (FDA) foi fornecido individualmente ( $2 \mathrm{~kg} / \mathrm{vaca} / \mathrm{dia})$ durante as ordenhas.

Para trabalhar com três vacas/piquete, e concomitantemente assegurar taxa de lotação uniforme entre tratamentos (5 vacas/ha), os piquetes variaram em número e tamanho (11 ou 16 piquetes, medindo 607 ou $417 \mathrm{~m}^{2}$, respectivamente para períodos de descanso de 30 ou 45 dias). 
No intervalo entre as duas ordenhas diárias, as vacas receberam, no curral, cana-de-açúcar (Saccharum officinarum, L.) picada corrigida com 1\% de uréia:sulfato de amônio (9:1) à vontade. A entrada das vacas nos piquetes de capim-elefante ocorreu após a ordenha da tarde e aí permaneceram até a ordenha da manhã seguinte.

Para amostragem do capim-elefante selecionado no pasto, foram usados dois bovinos adultos fistulados no esôfago. Foram colhidas, em agosto de 1993, amostras de extrusas referentes ao primeiro, segundo e terceiro dias de ocupação do piquete, em cada uma das duas repetições de área de pastagem de cada tratamento, originando um total de 18 materiais (três tratamentos $\times$ três dias de ocupação do piquete $\times$ duas repetições de área de pastagem).

Com o término das coletas diárias, as extrusas foram armazenadas a $-10^{\circ} \mathrm{C}$, sendo, posteriormente, descongeladas, homogeneizadas e pré-secas em estufa de ventilação forçada $\left(65^{\circ} \mathrm{C}, 72 \mathrm{~h}\right)$. Frações de cada material foram moídas (1mm) e analisadas segundo recomendações gerais de Silva (1998), quanto aos teores de MS, PB, FDN e FDA. A quantidade restante de cada um dos 18 materiais foi moída (5mm), visando ao estudo da degradação ruminal in situ (Nocek, 1988) da MS, PB e FDN. Os seis materiais pertencentes ao mesmo tratamento (extrusas de primeiro, segundo e terceiro dias de pastejo $\times$ duas repetições de área de pastagem) foram incubados no rúmen das duas vacas fistuladas daquele tratamento. Foram usados sacos de náilon ( $46 \mu$ de abertura de malhas; $18 \times 7,5 \mathrm{~cm}$ de dimensão), com cerca de $20 \mathrm{mg}$ de amostra por $\mathrm{cm}^{2}$ (Nocek, 1988).

Antes da incubação, todos os sacos foram mergulhados em água (temperatura ambiente, 30min). Os referentes ao tempo zero (estimativa da fração solúvel mais partículas com tamanho reduzido que atravessam os poros do náilon) foram retirados e congelados $\left(-10^{\circ} \mathrm{C}\right)$. Os demais foram colocados no rúmen e retirados 2, 6, 12, 24, 48 e 72h após a incubação, sendo também congelados. Todos os sacos foram descongelados, lavados simultaneamente, secos em estufa de ventilação forçada $\left(65^{\circ} \mathrm{C}, 72 \mathrm{~h}\right)$, pesados, e nos resíduos analisados quanto aos teores de MS, PB e FDN.

Os parâmetros de degradação ruminal in situ foram estimados pelo processo iterativo do algoritmo Marquardt, com auxílio do procedimento para modelos não-lineares (PROC NLIN) do SAS... (1985). Os dados de degradação parcial foram ajustados segundo a equação proposta por Mehrez e Ørskov (1977) modificada por Sampaio (1988). Os tempos de colonização (lag-time) foram calculados à semelhança do realizado por Figueira (1991). Posteriormente, os parâmetros da equação foram novamente estimados sem os dados referentes aos tempos de incubação inferiores ao lag-time calculado.

Os parâmetros da equação foram estimados para cada uma das nove condições estudadas (três tratamentos $\times$ três dias de pastejo), a partir da utilização conjunta dos dados das quatro repetições disponíveis (duas vacas fistuladas $\times$ duas repetições de área de pastagem). Ressalte-se que a análise de variância de parâmetros obtidos de equações individuais (rodadas por animal) não tem respaldo estatístico para sua execução (uma vez que todos já são estimativas). Assim, a discussão dos resultados será feita pela comparação direta das estimativas dos principais parâmetros cinéticos que representam o fenômeno de degradação ruminal in situ de cada condição estudada.

As determinações da degradabilidade efetiva (DE) foram feitas de acordo com o modelo proposto por Ørskov e McDonald (1979).

Foram feitas amostragens diárias do concentrado e da cana + uréia, sendo transformadas em compostas e analisadas conforme relatado para extrusa.

O segundo experimento foi conduzido na estação das chuvas (março e abril) de 1995. Foram usadas 12 vacas Holandês $\times$ Zebu em lactação, sendo quatro fistuladas no rúmen, estas últimas, em média, com $166 \pm 7$ dias da terceira ou quarta lactação. Foram estudados dois períodos de descanso da pastagem de capim-elefante (30 ou 45 dias) sem qualquer suplementação. Os demais procedimentos metodológicos e 
estatísticos, bem como os referentes ao delineamento global do experimento, foram feitos à semelhança dos relatados para o primeiro experimento.

\section{RESULTADOS E DISCUSSÃO}

Na Tab. 1 é apresentada a composição química média das extrusas usadas nas estimativas da degradação ruminal in situ dos nutrientes do capim-elefante. Foram verificados decréscimos nas concentrações de PB e, de forma inversa, incrementos nos teores de FDN e FDA nas extrusas coletadas do primeiro para o terceiro dia de ocupação dos piquetes. Resultados semelhantes foram observados por Cóser et al. (2000) e Aroeira et al. (2001). É provável que as distintas oportunidades ao pastejo seletivo, permitidas pela decrescente disponibilidade de pastagem, conseqüência do avanço nos dias de ocupação dos piquetes, tenham sido responsáveis pelas diferenças observadas na qualidade média diária da forragem ingerida no pasto.

Tabela 1. Composição química média das extrusas de capim-elefante por período de descanso (com ou sem suplementação concentrada da pastagem) e dia de ocupação do piquete

\begin{tabular}{|c|c|c|c|c|c|}
\hline \multirow{2}{*}{ Extrusa } & \multirow{2}{*}{$\begin{array}{c}\text { Dia de ocupação } \\
\text { do piquete }\end{array}$} & \multirow{2}{*}{$\begin{array}{l}\text { MS } \\
(\%)\end{array}$} & \multicolumn{3}{|c|}{ Componente da MS $(\%)^{1}$} \\
\hline & & & PB & FDN & FDA \\
\hline \multicolumn{6}{|c|}{ Experimento conduzido na estação da seca (1993) } \\
\hline \multirow{3}{*}{30 dias sem concentrado } & 1 & 11,4 & 16,7 & 72.9 & 41.0 \\
\hline & 2 & 11,2 & 10,2 & 77,3 & 45,0 \\
\hline & 3 & 12,4 & 8,6 & 78,3 & 44,8 \\
\hline \multirow{3}{*}{30 dias com concentrado } & 1 & 10,4 & 15,9 & 74,8 & 42,7 \\
\hline & 2 & 11,2 & 10,5 & 75,8 & 43,9 \\
\hline & 3 & 11,0 & 8,0 & 78,9 & 47,3 \\
\hline \multirow{3}{*}{45 dias com concentrado } & 1 & 11,3 & 12,4 & 76,7 & 46,6 \\
\hline & 2 & 12,1 & 8,7 & 79,5 & 46,7 \\
\hline & 3 & 12,1 & 7,7 & 76,7 & 51,3 \\
\hline \multicolumn{6}{|c|}{ Experimento conduzido na estação das chuvas (1995) } \\
\hline \multirow{3}{*}{30 dias sem concentrado } & 1 & 10,8 & 16,0 & 66,4 & 40,1 \\
\hline & 2 & 10,4 & 13,3 & 72,7 & 45,8 \\
\hline & 3 & 9,1 & 11,6 & 73,2 & 45,1 \\
\hline \multirow{3}{*}{45 dias sem concentrado } & 1 & 10,5 & 13,5 & 73,0 & 45,0 \\
\hline & 2 & 9,3 & 11,2 & 80,4 & 47,4 \\
\hline & 3 & 8,7 & 9,8 & 75,6 & 47,6 \\
\hline
\end{tabular}

${ }^{1} \mathrm{MS}=$ matéria seca; $\mathrm{PB}=$ proteína bruta; FDN= fibra em detergente neutro; FDA= fibra em detergente ácido.

Independentemente da estação do ano, verificou-se melhor qualidade nutritiva das extrusas da pastagem com período de descanso de 30 em relação à de 45 dias. Resultado semelhante foi apresentado por Deresz (1994). Ainda que delineados para o estudo de específicas faixas de maturidade da planta, vários trabalhos evidenciaram que o avanço no período de crescimento do capim-elefante esteve sempre associado a decréscimos no seu valor nutricional, principalmente com redução nos teores de PB e concomitante elevação na concentração de componentes fibrosos (FDN e FDA) e lignina (Deschamps, 1994; Vieira et al., 1997).

A composição química média da cana-de-açúcar corrigida com $1 \%$ de uréia:sulfato de amônio (MS= 29,7\%; $\mathrm{PB}=10,6 \%$; $\mathrm{FDN}=57,8 \%$ e $\mathrm{FDA}=34,6 \%$ ), usada como suplemento volumoso da pastagem de capim-elefante na estação seca foi próxima de valores da literatura (Aroeira et al., 1999; Lopes, Aroeira, 1999).

Nas Tab. 2 e 3 são apresentadas as médias calculadas, respectivamente por períodos de descanso (com ou sem suplementação concentrada da pastagem) e dias de ocupação do piquete, dos parâmetros taxa (c) e 
potencial de degradação (A), e degradabilidade efetiva (DE) da MS, PB e FDN das extrusas do capimelefante.

O modelo usado por Sampaio (1988) ajustou-se de modo satisfatório aos dados de degradação parcial da MS e FDN das extrusas. Os coeficientes de determinação $\left(\mathrm{R}^{2}\right)$ obtidos para as curvas de degradabilidade desses nutrientes, próximos ou superiores a 90\%, parcialmente atestaram a adequacidade desse modelo para caracterização do fenômeno. Para degradação ruminal in situ da $\mathrm{PB}$, alguns baixos $\mathrm{R}^{2}$ e elevados tempos de colonização sinalizaram problemas no ajuste do modelo aos dados de degradação desse nutriente, o que pode ser explicado pela contaminação microbiana (Valadares Filho, 1994) para a qual, no presente estudo, não foi adotado procedimento de correção.

Tabela 2. Degradabilidade efetiva (DE), taxa (c) e potencial de degradação (A) da matéria seca (MS), proteína bruta (PB) e fibra em detergente neutro (FDN) das extrusas de capim-elefante por período de descanso e suplementação concentrada

\begin{tabular}{lcccc}
\hline \multirow{2}{*}{ Tratamento } & \multirow{2}{*}{ Nutriente } & \multicolumn{3}{c}{ Parâmetros cinéticos } \\
\cline { 3 - 4 } & Experimento conduzido na estação da seca (1993) & DE (\%) $)^{1}$ \\
\hline 30 dias sem concentrado & MS & 0,023 & 84,8 & 42,6 \\
30 dias com concentrado & & 0,028 & 82,0 & 42,6 \\
45 dias com concentrado & & 0,023 & 79,7 & 37,0 \\
30 dias sem concentrado & PB & 0,023 & 88,4 & 46,0 \\
30 dias com concentrado & & 0,024 & 87,7 & 40,6 \\
45 dias com concentrado & FDN & 0,020 & 89,4 & 37,7 \\
30 dias sem concentrado & & 0,023 & 83,3 & 32,8 \\
30 dias com concentrado & & 0,028 & 79,0 & 34,0 \\
45 dias com concentrado & & 0,023 & 77,1 & 29,2 \\
& & & \\
30 dias sem concentrado & Experimento conduzido na estação das chuvas (1995) & 55,2 \\
45 dias sem concentrado & MS & 0,037 & 84,1 & 50,2 \\
30 dias sem concentrado & & 0,034 & 83,4 & 60,3 \\
45 dias sem concentrado & PB & 0,033 & 91,4 & 53,3 \\
30 dias sem concentrado & & 0,032 & 88,7 & 44,7 \\
45 dias sem concentrado & FDN & 0,041 & 79,4 & 41,9 \\
\hline
\end{tabular}

${ }^{1}$ Valores calculados, considerando taxas de passagem ruminal concomitantemente estimadas (usando modelo de Grovum, Williams, 1973), com auxílio da técnica da FDN-cromo-mordente. 
Tabela 3. Degradabilidade efetiva (DE), taxa (c) e potencial de degradação (A) da matéria seca (MS), proteína bruta (PB) e fibra em detergente neutro (FDN) das extrusas de capim-elefante por dia de pastejo

\begin{tabular}{|c|c|c|c|c|}
\hline \multirow{2}{*}{$\begin{array}{l}\text { Dia de ocupação } \\
\text { do piquete }\end{array}$} & \multirow{2}{*}{ Nutriente } & \multicolumn{3}{|c|}{ Parâmetros cinéticos } \\
\hline & & c $(/ \mathrm{h})$ & $\mathrm{A}(\%)$ & $\mathrm{DE}(\%)^{1}$ \\
\hline \multicolumn{5}{|c|}{ Experimento conduzido na estação da seca (1993) } \\
\hline 1 & MS & 0,024 & 83,4 & 41,1 \\
\hline 2 & & 0,030 & 80,9 & 44,6 \\
\hline 3 & & 0,020 & 82,1 & 36,4 \\
\hline 1 & $\mathrm{~PB}$ & 0,023 & 90,0 & 42,2 \\
\hline 2 & & 0,031 & 87,4 & 46,4 \\
\hline 3 & & 0,020 & 88,2 & 35,8 \\
\hline 1 & FDN & 0,024 & 80,9 & 31,0 \\
\hline 2 & & 0,028 & 78,0 & 37,4 \\
\hline 3 & & 0,019 & 80,5 & 27,6 \\
\hline \multicolumn{5}{|c|}{ Experimento conduzido na estação das chuvas (1995) } \\
\hline 1 & MS & 0,038 & 84,7 & 55,3 \\
\hline 2 & & 0,029 & 85,0 & 47,9 \\
\hline 3 & & 0,039 & 81,5 & 54,9 \\
\hline 1 & PB & 0,034 & 93,0 & 60,7 \\
\hline 2 & & 0,029 & 90,0 & 50,2 \\
\hline 3 & & 0,036 & 87,3 & 59,5 \\
\hline 1 & FDN & 0,033 & 78,5 & 45,1 \\
\hline 2 & & 0,028 & 80,0 & 39,2 \\
\hline 3 & & 0,036 & 79,3 & 45,7 \\
\hline
\end{tabular}

${ }^{1}$ Valores calculados, considerando taxas de passagem ruminal concomitantemente estimadas com auxílio da técnica da FDN-cromomordente, usando modelo de Grovum e Williams (1973).

Os parâmetros de degradabilidade ruminal in situ da MS variaram dentro dos limites relatados na literatura para capim-elefante verde picado em bovinos em crescimento (Deschamps, 1994; Barbi et al., 1995; Kariuki et al., 1998; Malafaia et al., 1998). Os valores de degradabilidade potencial e efetiva da MS, PB e FDN apresentados nas Tab. 2 e 3 foram, em geral, superiores aos relatados por Lopes e Aroeira (1998), que trabalharam com vacas Holandês $\times$ Zebu em lactação em dieta à base de capim-elefante picado suplementado (3,3kg/vaca/dia) ou não com concentrado. Para taxas de degradação da MS, PB e FDN, os valores obtidos foram superiores aos apresentados por esses autores.

Dados da dinâmica da degradação ruminal in situ dos nutrientes do capim-elefante sob pastejo de bovinos são restritos à literatura nacional (Benedetti, 1994; Balsalobre et al., 1996; Codagnone et al., 1998; Lopes, Aroeira, 1999). No presente estudo, foram estimadas taxas de degradação ruminal da MS e FDN superiores às relatadas por Balsalobre et al. (1996) em amostras de capim-elefante coletadas no verão, simulando o pastejo e incubadas em vacas Holandesas não-lactantes. No entanto, as taxas de degradação obtidas foram inferiores às relatadas para vacas Holandês $\times$ Zebu em lactação em pastagem de capimelefante suplementada com concentrado na estação das chuvas (Benedetti, 1994) e, adicionalmente, com cana mais uréia na seca (Lopes, Aroeira, 1999). Os valores de degradabilidade potencial da MS, PB e FDN obtidos foram superiores aos relatados por Lopes e Aroeira (1999), mas as estimativas de degradabilidade efetiva desses nutrientes foram, de modo geral, similares às calculadas por esses autores. Os dados de degradabilidade potencial e efetiva da MS apresentados nas Tab. 2 e 3 foram similares aos relatados por Benedetti (1994), e para PB e FDN foram, respectivamente, superiores e inferiores.

Com relação aos períodos de descanso da pastagem, os resultados (Tab. 2) indicaram que o avanço na idade de crescimento do capim-elefante correspondeu ao decréscimo na sua degradabilidade efetiva. Quanto às pastagens com suplementação concentrada nas estações da seca e das chuvas, verificaram-se maiores taxas de degradação dos nutrientes (MS, PB e FDN) nas pastagens com períodos de 30 dias de descanso. 
Os dados de degradabilidade potencial sugerem pequena diferença em favor do período de descanso mais curto. Tendências semelhantes foram relatadas para MS e FDN do capim-elefante (Barbi et al., 1995; Ayala-Burgos et al., 2000).

Especificamente com relação aos dias de ocupação do piquete, independentemente dos períodos de descanso da pastagem, os valores médios de degradabilidade efetiva da MS, PB e FDN observados na estação da seca demonstraram superioridade dos dois primeiros dias em relação ao último. No experimento da estação das chuvas praticamente não houve diferença entre o primeiro e terceiro dias de ocupação do piquete para degradabilidade efetiva, independentemente do período de descanso da pastagem. Quanto ao segundo dia de ocupação do piquete, em ambos experimentos, os resultados médios de degradabilidade efetiva divergiram do óbvio biologicamente esperado. Por certo, o sinergismo da combinação das taxas de degradação e de passagem nos cálculos da degradabilidade efetiva foi decisivo na geração dos valores obtidos.

Na literatura consultada, apenas Codagnone et al. (1998) fizeram estudo comparativo da degradabilidade efetiva da MS, em diferentes dias de ocupação do piquete. Esses autores, em pastagens rotacionadas de capim-elefante, com 45 dias de período de descanso, pastejadas por vacas em lactação entre as ordenhas da tarde e da manhã seguinte, observaram valores de degradabilidade efetiva da MS, respectivamente, de 64,3 e 56,7\%, para amostras da forragem (corte a $40 \mathrm{~cm}$ do solo) disponível no primeiro e segundo dias de ocupação dos piquetes.

Os dados médios apresentados na Tab. 2 para as pastagens com 30 dias de descanso na estação da seca indicaram que nenhum benefício mais aparente com respeito às degradabilidades potencial e efetiva pode ser atribuído à suplementação concentrada. Foi verificado apenas ligeiro incremento na taxa de degradação dos nutrientes do capim-elefante.

\section{CONCLUSÕES}

Na estação das chuvas a degradabilidade efetiva dos nutrientes do capim-elefante, em especial da FDN, manteve-se em níveis satisfatórios, mesmo no último dia de ocupação dos piquetes, comprovando a boa qualidade nutritiva da forrageira nessa época do ano e, parcialmente, explicando seu elevado consumo por vacas em lactação. Em face dos maiores valores de degradabilidade efetiva obtidos e, adicionalmente, dos menores investimentos exigidos na divisão da pastagem em piquetes, recomenda-se a adoção de 30 dias de período de descanso.

\section{REFERÊNCIAS BIBLIOGRÁFICAS}

AROEIRA, L.J.M.; LOPES, F.C.F.; DERESZ, F. et al. Daily intake of lactating crossbred cows grazing elephant grass rotationally. Pesq. Agropec. Bras., v.36, p.911-917, 2001.

AROEIRA, L.J.M.; LOPES, F.C.F.; DERESZ, F. et al. Pasture availability and dry matter intake of lactating crossbred cows grazing elephant grass (Pennisetum purpureum, Schum.). Anim. Feed Sci. Technol., v.78, p.313-324, 1999.

AYALA-BURGOS, A.J.; DeB HOVELL, F.D.; GODOY, R.M. et al. Effect of maturity of Napier grass (Pennisetum purpureum) hay on intake, digestibility, and rumen dynamics when given to zebu bulls. In: SOCIETY OF ANIMAL PRODUCTION MEETING, 2000, Scaraborough. Proceedings... Scaraborough: British of Society of Animal Production, 2000. p.144.

BALSALOBRE, M.A.A.; CORSI, M.; SANTOS, P.M. Avaliação da digestibilidade in situ de amostras simulando o pastejo em capim-elefante (Pennisetum purpureum Schum.). In: REUNIÃO ANUAL DA SOCIEDADE BRASILEIRA DE ZOOTECNIA, 33., Fortaleza, 1996. Anais... Fortaleza: SBZ, 1996. p.274-276. 
BARBI, J.T.H.; SAMPAIO, I.B.M.; MAURÍCIO, R.M. Avaliação de quatro gramíneas tropicais em diferentes idades de corte pela técnica “in situ”. Arq. Bras. Med. Vet. Zootec., v.47, p.73-86, 1995.

BENEDETTI, E. Atributos de três gramíneas tropicais, parâmetros ruminais e produção de leite em vacas mestiças mantidas a pasto. 1994. 173f. Tese (Doutorado) - Escola de Veterinária, Universidade Federal de Minas Gerais, Belo Horizonte.

CODAGNONE, H.C.; VIEIRA, A.M.; LEME, M.C. et al. Qualidade do capim-elefante em sistema de pastejo rotacionado. In: REUNIÃO ANUAL DA SOCIEDADE BRASILEIRA DE ZOOTECNIA, 35., Botucatu, 1998. Anais... Botucatu: SBZ, 1998. v.2. p.722-724.

CÓSER, A.C.; MARTINS, C.E.; DERESZ, F. A pesquisa em produção de leite a pasto na Embrapa Gado de Leite - 1980 a 1999. Juiz de Fora: Embrapa Gado de Leite, 2000. 32p. (Embrapa Gado de Leite. Circular Técnica, 61).

DERESZ, F. Manejo da pastagem de capim-elefante para produção de leite e carne. In: SIMPÓSIO SOBRE CAPIM-ELEFANTE, 2., 1994, Juiz de Fora. Anais... Coronel Pacheco: EMBRAPA-CNPGL, 1994. p.116138.

DESCHAMPS, F.C. Degradabilidade ruminal da matéria seca e da proteína de alguns alimentos utilizáveis na alimentação de ruminantes. Rev. Soc. Bras. Zootec., v.23, p.898-908, 1994.

FIGUEIRA, D.G. Efeito do nível de uréia sobre as digestibilidades aparente e "in situ" e a dinâmica da fase sólida em bovinos alimentados com cana-de-açúcar e farelo de algodão. 1991. 123f. Tese (Mestrado) Escola de Veterinária, Universidade Federal de Minas Gerais, Belo Horizonte.

GROVUM, W.L.; WILLIAMS, V.J. Rate of passage of digesta in sheep. 4.* Passage of marker through the alimentary tract and the biological relevance of rate-constants derived from the changes in concentration of marker in faeces. Br. J. Nutr., v.30, p.313-329, 1973.

KARIUKI, J.N.; GITAU, G.K.; GACHUIRI, C.K. et al. Effect of supplementating napier grass, with desmodium and lucerne on intake and weight gains in dairy heifers. In: KARIUKI, J.N. The potencial of improving napier grass under smallholder dairy farmers' conditions in Kenya. Wageningen: Grafish Service Centrum, 1998. Chapter 7, p.109-122.

LOPES, F.C.F.; AROEIRA, L.J.M. Consumo, digestibilidade e degradabilidade do capim-elefante (Pennisetum purpureum Schum.) picado e seu efeito sobre características do rúmen em vacas mestiças. Arq. Bras. Med. Vet. Zootec., v.50, p.593-599, 1998.

LOPES, F.C.F.; AROEIRA, L.J.M. Degradabilidade do capim-elefante (Pennisetum purpureum Schum.) e da cana-de-açúcar (Saccharum officinarum, L.) mais uréia no rúmen de vacas mestiças Holandês $\times$ Zebu em lactação. Arq. Bras. Med. Vet. Zootec., v.51, p.383-386, 1999.

MALAFAIA, P.A.M.; VALADARES FILHO, S.C.; VIEIRA, R.A.M. et al. Cinética ruminal de alguns alimentos investigada por técnicas gravimétricas e metabólicas. Rev. Bras. Zootec., v.27, p.370-380, 1998.

MEHREZ, A.Z.; ØRSKOV, E.R.A study of the artificial fibre bag technique for determining the digestibility of feeds in the rumen. J. Agric. Sci., v.88, p.645-650, 1977.

NOCEK, J.E. In situ and other methods to estimate ruminal protein and energy digestibility. A review. J. Dairy Sci., v.71, p.2051-2069, 1988.

NATIONAL Research Council. Nutrients requirements of dairy cattle. 7.ed. Washington: Natl. Acad. Sc., 2001. 408p.

ØRSKOV, E.R.; McDONALD, I. The estimation of protein degradability in the rumen from incubation measurements weighted according to rate of passage. J. Agric. Sci., v.92, p.499-503, 1979. 
SAMPAIO, I.B.M. Experimental designs and modelling techniques in the study of roughage degradation in rumen and growth of ruminant. 1988. 228f. Thesis (Phylosophy Doctor) - University of Reading, Reading.

SAS Institute Inc. SAS ${ }^{\circledR}$ User's Guide: Statistics, Version 5 Edition. Cary, NC: SAS Institute Inc., 1985. 956p.

SILVA, D.J. Análise de alimentos. Viçosa, UFV, Imprensa Universitária da UFV, 1998. 166p.

VALADARES FILHO, S.C. Utilização da técnica in situ para avaliação de alimentos. In: SIMPÓSIO INTERNACIONAL DE PRODUÇÃO DE RUMINANTES, 1994, Maringá. Anais... Maringá: EDUEM, 1994. p.95-118.

VIEIRA, R.A.M.; PEREIRA, J.C.; MALAFAIA, P.A.M. et al. The influence of elephant-grass (Pennisetum purpureum Schum., Mineiro variety) growth on the nutrient kinetics in the rumen. Anim. Feed Sci. Technol., v.67, p.151-161, 1997. 